\title{
Where Pain Meets Action in the Human Brain
}

\author{
Irene Perini, ${ }^{1,2}$ Simon Bergstrand, ${ }^{1}$ and India Morrison ${ }^{1,2,3}$ \\ ${ }^{1}$ Department of Clinical Neurophysiology, Sahlgrenska University Hospital, S-413 45, Gothenburg, Sweden, ${ }^{2}$ Institute of Neuroscience and Physiology, \\ University of Gothenburg, S-413 90, Gothenburg, Sweden, and ${ }^{3}$ Department of Cognitive Neuroscience and Philosophy, University of Skövde, S-541 28, \\ Skövde, Sweden
}

Pain's complex influence on behavior implies that it involves an action component, although little is known about how the human brain adaptively translates painful sensations into actions. The consistent activation of premotor and motor-related regions during pain, including the midcingulate cortex (MCC), raises the question of whether these areas contribute to an action component. In this fMRI experiment, we controlled for voluntary action-related processing during pain by introducing a motor task during painful or nonpainful stimulation. The MCC (particularly the caudal cingulate motor zone [CCZ]), motor cortex, thalamus, and cerebellum responded during action regardless of pain. Crucially, however, these regions did not respond to pain unless an action was performed. Reaction times were fastest during painful stimulation and correlated with CCZ activation. These findings are consistent with the results of an activation likelihood estimate meta-analysis in which activation across experiments involving pain, action execution, or action preparation (with a total of 4929 subjects) converged in a similar network. These findings suggest that specific motor-related areas, including the CCZ, play a vital role in the control and execution of context-sensitive behavioral responses to pain. In contrast, bilateral insular cortex responded to pain stimulation regardless of action.

\section{Introduction}

The decisive motivational influence of pain on behavior is reflected in the apt old Roman saying dolor dictat, roughly translated as "pain calls the shots." Normal acute pain modulates both autonomic and skeletomotor efference (Piché et al., 2010). Cortical pain processing thus not only involves a sensory and affective representation of nociceptive input but also provides the means for the adaptive modification of behavior through efferent channels. Subjectively, this is probably experienced as an imperative desire to escape or avoid the source of pain, or as the preparedness to do so.

But adaptive behavioral responses to pain depend on context and circumstances, which can occasionally call for control or suppression of movement. For example, imagine you are a volunteer in a pain neuroimaging experiment. You are instructed to remain as still as possible, yet when the painful stimulus comes you struggle not to wince. Because you wish to be a cooperative subject, you override your impulses to avoid pain as your brain is scanned. This example illustrates how acute pain can require complex control over behavior. It also points to a difficulty often overlooked in fMRI studies of pain: because movement is usually minimized in the scanner, brain responses to pain may partially reflect motor processing (Farrell et al., 2005).

\footnotetext{
Received July 2, 2012; revised July 10, 2013; accepted July 14, 2013.

Author contributions: I.M. designed research; I.P. and S.B. performed research; I.P., S.B., and I.M. analyzed data; I.P. and I.M. wrote the paper.

This work was supported by Swedish Research Council Grant 2010-2120 to I.M. We thank Tomas Karlsson, Håkan Olausson, Rochelle Ackerley, Giuseppe di Pellegrino, Luiz Pessoa, and Yazdan Shirvany for their valuable assistance and advice.

The authors declare no competing financial interests.

Correspondence should be addressed to Dr. India Morrison, Department of Clinical Neurophysiology, Blå stråket 7, Sahlgrenska University Hospital, S-413 45, Gothenburg, Sweden. E-mail: india.morrison@neuro.gu.se.

DOI:10.1523/JNEUROSCI.3135-12.2013

Copyright $\odot 2013$ the authors $\quad 0270-6474 / 13 / 3315930-10 \$ 15.00 / 0$
}

One of the cortical brain regions most consistently implicated in the processing of pain stimulation during neuroimaging experiments is the midcingulate cortex (MCC) (Shackman et al., 2011; Duerden and Albanese, 2013). This region on the medial wall of the hemisphere also contains premotor areas called cingulate motor areas (CMAs) in macaques and cingulate motor zones (CMZs) in humans (Matelli et al., 1991; Shima and Tanji, 1998; Deiber et al., 1999). The CMAs have direct projections to primary motor cortex and spinal motoneurons (Dum and Strick, 1992) and also receive spinothalamic input from a nociceptive pathway (Dum et al., 2009). This anatomical organization suggests that the CMAs are involved in the cortical control of voluntary movement during painful stimulation (Vogt and Morecraft, 2009; Vogt and Sikes, 2009).

Here we asked whether some of the brain regions consistently activated by pain in fMRI studies, medial premotor areas such as the CMZs in particular, could reflect motor processing related to voluntary action. One alternative is that motor responses to pain are processed by the brain distinctly from the nociceptive input (Kwan et al., 2000). In this case, pain and action would be independently processed, perhaps in separate regions or subregions. Another alternative is that the normal cortical response to acute pain involves recruitment of motor-related processes contributing to control of voluntary action. In this case, the action factor may even account for some regions' functional engagement by painful stimuli. The present study tests this possibility by distributing a button press task across both pain and nonpain conditions, thus controlling for voluntary action during pain. Balancing pain and action factors in this way allowed us to discover and probe any relationship of pain responses with action-related processing.

\section{Materials and Methods}

Participants and image acquisition. Eighteen right-handed healthy subjects ( 9 males), 21-33 years of age were scanned with a PHILIPS Achieva 3-Tesla scanner with a SENSE head coil. Echo-planar imaging sequence 
STIMULATION

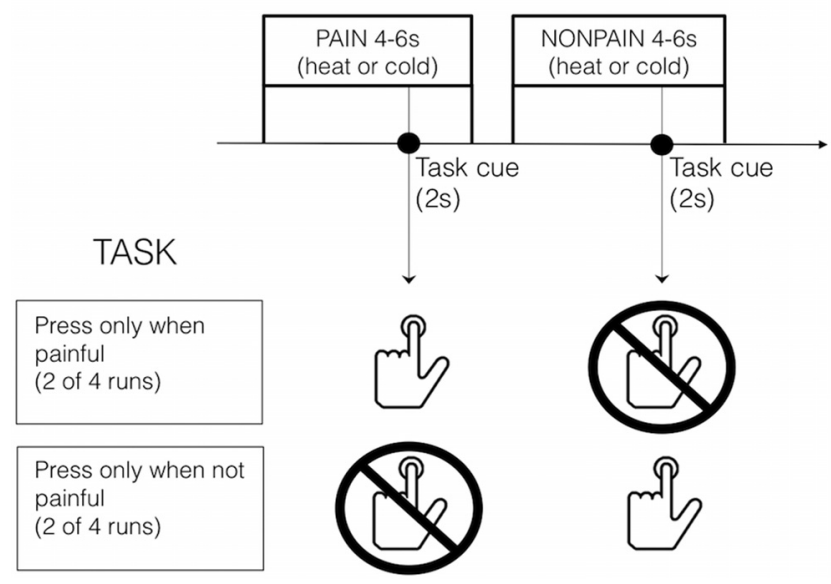

Figure 1. Design and task. Diagram shows schematic structure of thermal stimulus application (pain or nonpain) and task (press or refrain from pressing a button). Rectangles represent duration of stimulation from onset to offset; the thermode was at target temperature for the entire period in each trial. During stimulation, the task cue (black fixation dot) appeared $1 \mathrm{~s}$ before stimulus offset and remained on for $2 \mathrm{~s}$ (until $1 \mathrm{~s}$ poststimulus offset). On cue appearance participants pressed a button when stimulation was painful (for 2 of the 4 runs) or nonpainful (for the other 2 runs). The intersection of the voluntary button-press task with any pain-related motor potentiation processes was designed to capture behavioral and neural relationships between voluntary action and acute pain processing.

was used to acquire the whole brain (T2*-weighted, gradient echo sequence, repetition time $=3000 \mathrm{~ms}$, echo time $=35 \mathrm{~ms}$, flip angle $=90^{\circ}$, FOV $200 \times 244 \times 128,46$ axial slices, $2.79 \mathrm{~mm}$ thick, with no gap), voxel size $1.72 \times 1.72 \times 2.80 \mathrm{~mm}$. To minimize head movement, participants' heads were stabilized with a vacuum hood filled with polystyrene balls (Vacuform Hood, Cambridge Research Systems). Ethical approval was obtained by the ethics board of Gothenburg University. Participants gave informed consent in accordance with the Declaration of Helsinki and were compensated at 200 Swedish crowns/h.

Stimuli and thresholding. All thermal stimuli were delivered with a $30 \times 30 \mathrm{~mm}$ Thermal Stimulator Probe (PATHWAY Model ATS, Medoc). Before scanning, individuals' discriminative and pain thresholds for heat and cold were obtained. Discriminative thermal thresholds were determined by a procedure in which thermode temperature started from a baseline of $32^{\circ} \mathrm{C}$ and increased (for heat) or decreased (for cold) at $1^{\circ} \mathrm{C} / \mathrm{s}$. The participants were asked to click a mouse button positioned on the right hand as soon as they perceived a change in the temperature. Similarly, pain thresholding started from a baseline temperature of $32^{\circ} \mathrm{C}$ and increased or decreased until the participant pressed the button to stop the ramping as soon as the stimulus was perceived as painful. Stimulation temperatures in the fMRI experiment were based on the resulting individual thresholds (the same temperatures for nonpainful trials, $2^{\circ} \mathrm{C}$ added for heat pain, and $2^{\circ} \mathrm{C}$ subtracted from cold pain).

Design. A series of 24 thermal stimulations/block (painful and nonpainful heat and cold) was delivered on the dorsal part of the left hand (Figure 1). The stimuli were pseudorandomized within four different sequences in four separate runs, counterbalanced across subjects. In each trial, the duration of the stimulation was $4 \mathrm{~s}$ for heat and $6 \mathrm{~s}$ for cold. The experimenter (I.P.) was positioned beside the participant in the scanner and followed cues on a screen (not visible to the participant) indicating the timing of thermode onset and offset for manual stimulus delivery. In all trials, the thermode had reached the target temperature before it was applied to the participant's hand. The thermode did not contact the participants' hands during ramping, which occurred at a rate of $1^{\circ} \mathrm{C} / \mathrm{s}$ during the interstimulus interval. The interstimulus interval varied from 10 to $50 \mathrm{~s}$. The task varied by block. In 2 of the 4 blocks, participants were instructed to respond as quickly as possible to painful but not to nonpainful stimulation, upon the appearance of a visual cue (a dot) $1 \mathrm{~s}$ before the offset of thermal stimulation ( $3 \mathrm{~s}$ after stimulus onset for heat trials, $5 \mathrm{~s}$ after onset for cold trials). In this way, the button press responses were time-locked to the cue. The cue remained on the screen for $2 \mathrm{~s}$ (from $1 \mathrm{~s}$ before $1 \mathrm{~s}$ poststimulus offset). In the other half of the blocks, participants responded only if the stimulation was nonpainful. Responses were made with the right hand using a response pad system (4-Button Diamond Fiber Optic Response Pad, Current Designs). Reaction times (RTs) and accuracy were recorded. Because the design aimed to capture general motor facilitation, stimulation was delivered to the nonresponse (left) hand to reduce potential confounds between stimulus- and response-related activations and to limit any effects of the thermode device on button press fluency. Including both heat and cold allowed us to investigate types of pain carrying different behavioral consequences and involving different afferent systems (Fruhstorfer, 1976; Norrsell and Ullman, 1978).

Urge-to-move and intensity ratings. A separate group $(n=15,8 \mathrm{fe}-$ males) underwent two thermal stimulation blocks of 24 thermal stimulations identical to those in the fMRI experiment. The participants were stimulated on the dorsal part of the left hand while holding a mouse in their right hand. During the stimulation, they were instructed to continuously rate their "urge to move" their hand away from the thermode by dragging the mouse on a visual analog scale (VAS) displayed on a computer screen, with anchor points "no urge" (1) and "strong urge" (10). In the other trial, they were instructed to continuously rate the intensity of the stimulation ("not intense" to "very intense").

To investigate the pattern of continuous ratings over time, each rating was fitted to a linear regression by using the MATLAB curve fitting toolbox (MathWorks). Given the difference in trial length ( $4 \mathrm{~s}$ for heat, $6 \mathrm{~s}$ for cold), we focused our analysis on the interval from 1 to $4 \mathrm{~s}$, which reflects the crucial differences in the course of the ratings for both heat and cold. The mean slope values were then compared within subjects.

fMRI data analysis. Preprocessing and statistical analysis of MRI data were performed using BrainVoyager QX 2.1 (Brain Innovation). Two dummy volumes were acquired before each scan to reduce possible effects of T1 saturation. Functional data were motion corrected, and lowfrequency drifts were removed with a temporal high-pass filter $(0.006$ $\mathrm{Hz}$ ). Spatial smoothing was applied with a $6 \mathrm{~mm}$ full-width at halfmaximum filter. Functional data were manually coregistered with $3 \mathrm{D}$ anatomical T1 scans $(1 \times 0.93 \times 0.93 \mathrm{~mm}$ resolution resampled to $1 \times$ $1 \times 1 \mathrm{~mm}$ ), on the basis of anatomical landmarks for each individual. The $3 \mathrm{D}$ anatomical scans were transformed into Talairach space (Talairach and Tournoux, 1988), and the parameters for this transformation were applied to the coregistered functional data. For each participant, general linear models were created for each of the four runs.

One predictor (convolved with a standard model of the hemodynamic response function, two $\gamma$ HRF) modeled each of the eight conditions (painful heat press, painful cold press, painful heat no-press, painful cold no-press; nonpainful heat press, nonpainful cold press, nonpainful heat no-press, nonpainful cold no-press). This enabled us to isolate and compare the activations involved in the motor execution within the painful and the nonpainful conditions. Each predictor modeled the $1 \mathrm{~s}$ interval beginning with the onset of the cue during the last second of stimulation. Whole-brain random-effects contrasts were thresholded at $t=3.22$ ( $p=$ 0.005) and corrected for multiple comparisons using BrainVoyager's cluster threshold estimator plug-in, which uses a Monte Carlo simulation procedure (1000 iterations) to establish the critical cluster size threshold corresponding to a familywise $\alpha$ of 0.05 corrected for the whole brain.

Activation likelihood estimate (ALE) meta-analyses. BrainMap's Sleuth software (version 1.2) was used to identify all studies in the BrainMap database (http://www.brainmap.org) that reported activation in three separate behavioral domains: (1) cutaneous pain (62 papers, $N=814$ ), (2) hand action execution (234 papers, $N=4019$ ), and (3) hand action preparation ( 9 papers, $N=92$ ).

For each meta-analysis, studies involving drug manipulations or patient populations were only included if they reported contrasts for healthy, drugfree controls. (For a related ALE analysis, see Morrison et al., 2013). Pain. The database search was limited to studies involving acute cutaneous pain (thermal including laser heat and cold pressor $58 \%$, electrical 23\%, mechanical $14 \%$, and chemical 5\%). Studies involving visceral, muscle, joint, or pathological pain were excluded, as those involving semantic or graphic manipulations without a pain-only condition (e.g., word stimuli independent of pain stimulation). The resulting dataset consisted of 62 papers with a total $N$ 
A

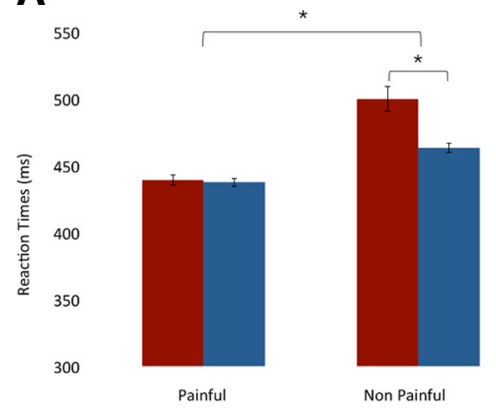

B

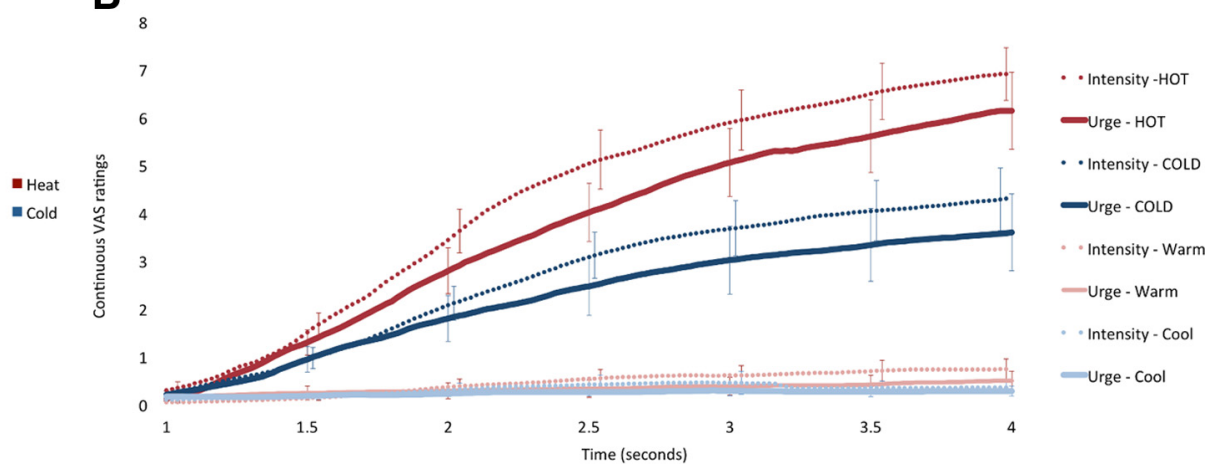

Figure 2. Behavioral results. $A$, Mean RTs across painful and nonpainful thermal stimulation for heat and cold, with a significant main effect of pain ( $p=0.006$ ) reflecting faster responses during painful stimulation $(n=18$ ). Error bars indicate SEM. $B$, Continuous ratings of an "urge to move" the hand away from the stimulus and stimulus intensity ratings, across painful and nonpainful thermal stimulation for heat and cold $(n=15)$. Mean slopes were significantly faster for painful compared with neutral conditions for both movement urge and stimulus intensity ratings ( $p<$ 0.001), with sharper rises for heat pain compared with cold pain $(p=0.01)$. HOT, Painful heat; COLD, painful cold; Warm, nonpainful heat; Cool, nonpainful cold.

of 814 subjects. Action execution. The database search was limited to studies involving actions made with the hand (regardless of handedness). Studies involving eye movements were excluded unless they reported contrasts for hand-only conditions. The resulting dataset consisted of 234 papers with a total $N$ of 4019 subjects. Action preparation. The database search was limited to studies involving actions made with the hand (regardless of handedness). Studies involving eye movements were excluded unless they reported contrasts for hand-only conditions. The resulting dataset consisted of 9 papers with a total $N$ of 92 subjects.

Coordinates for all meta-analyses were transformed to MNI space (stereotaxic coordinates of the Montreal Neurological Institute), where necessary. To determine the likely spatial convergence of reported activations across studies, the resulting coordinates were submitted to an ALE analysis, which accounts for spatial uncertainty, using GingerALE software (Turkeltaub et al., 2002; Laird et al., 2005; Eickhoff et al., 2009) and thresholded with a false discovery rate of $\mathrm{q}<0.05$. The resulting statistical maps were visualized on the MNI anatomical template using MRIcron software (http://www. mccauslandcenter.sc.edu/CRNL/). To discover voxel clusters activated for pain and action execution and action preparation, a three-way intersection (conjunction) analysis of these ALE maps, thresholded at $p<0.05$, was performed using spm5 (http://www.fil.ion.ucl.ac.uk/spm/software/spm5). To relate our cingulate activations to the meta-analysis results, peak coordinates from our fMRI study were transformed to MNI space using GingerALE's foci conversion tool (Turkeltaub et al., 2002; Laird et al., 2005; Lancaster et al., 2007; Eickhoff et al., 2009) and plotted on an MNI template.

\section{Results}

\section{Behavior}

Pain thresholds

Pain thresholds were $42^{\circ}-50^{\circ} \mathrm{C}$ (mean $46^{\circ} \mathrm{C}, \mathrm{SD}=2.25^{\circ} \mathrm{C}$, SEM $=$ $0.53^{\circ} \mathrm{C}$ ) for painful heat, and $-8^{\circ}$ to $5^{\circ} \mathrm{C}\left(\right.$ mean $-1^{\circ} \mathrm{C}, \mathrm{SD}=3.56^{\circ} \mathrm{C}$, $\mathrm{SEM}=0.84^{\circ} \mathrm{C}$ ) for painful cold. Discrimination thresholds for nonpainful temperatures were $32^{\circ}-38^{\circ} \mathrm{C}$ (mean $33^{\circ} \mathrm{C}, \mathrm{SD}=1.25^{\circ} \mathrm{C}$, SEM $=0.29^{\circ} \mathrm{C}$ ) for heat stimulation, and $28^{\circ}-31^{\circ} \mathrm{C}$ (mean $30^{\circ} \mathrm{C}$, $\mathrm{SD}=0.72^{\circ} \mathrm{C}, \mathrm{SEM}=0.17^{\circ} \mathrm{C}$ ) for cold stimulation.

$R T s$

Figure $2 A$ shows the response times for each condition. Subjects performed the task with at least $78 \%$ accuracy. Responses $<200$ $\mathrm{ms}$ and $>800 \mathrm{~ms}$ were excluded from the analysis. The mean correct response times were submitted to a $2 \times 2$ repeatedmeasures ANOVA with two within-subject factors: noxiousness (painful, nonpainful) and temperature (heat, cold). There was a significant interaction between the noxiousness of the thermal stimulation and its temperature $\left(F_{(1,17)}=6.782, p=0.01\right)$, indicating that noxiousness and temperature influenced each other. Responses were faster for painful stimuli, with main effects of both noxiousness $\left(F_{(1,17)}=9.646, p=0.006\right)$ and temperature $\left(F_{(1,17)}=8.718, p=0.009\right)$. There was no difference in RTs between heat and cold painful stimulation $\left(t_{(17)}=0.183, p=\right.$ 0.86 ), but RTs for nonpainful cold were faster than those for nonpainful heat $\left(t_{(17)}=3.78, p=0.001\right)$.

\section{Urge-to-move and intensity ratings}

A separate group of subjects $(n=15)$ provided continuous ratings of their "urge to move" their hand away from the painful stimulus in trials identical to those used in the scanner (Fig. 2B). For each condition in each subject, we submitted the mean urge-tomove slope values from a linear regression to a $2 \times 2$ repeatedmeasures ANOVA with factors noxiousness (painful, nonpainful) and temperature (heat, cold). Painful stimulation resulted in significantly higher slope values, with heat pain significantly greater than cold pain: significant main effects were found for both noxiousness $\left(F_{(1,14)}=52.330, p<0.001\right)$ and temperature $\left(F_{(1,14)}=8.215, p=\right.$ $0.012)$, together with an interaction between noxiousness and temperature $\left(F_{(1,14)}=7.166, p=0.018\right)$. Slope values were higher for painful compared with nonpainful heat $\left(t_{(14)}=7.355 p<0.001\right)$ and $\operatorname{cold}\left(t_{(14)}=4.762, p=0.0003\right)$. Further, within the pain conditions, slope values were significantly higher for heat pain compared with cold pain $\left(t_{(14)}=2.789, p=0.014\right)$.

As in the urge-to-move rating analysis, the mean intensity slope values were submitted to a $2 \times 2$ repeated-measures ANOVA with factors noxiousness (painful, nonpainful) and temperature (heat, cold). The pattern of results was similar to that of the urge-to-move ratings: significant main effects for noxiousness $\left(F_{(1,14)}=54.160, p<0.001\right)$ and temperature $\left(F_{(1,14)}=\right.$ $29.852, p<0.001)$ as well as an interaction between noxiousness and temperature $\left(F_{(1,14)}=17.278, p=0.001\right)$. Again, slope values were higher for painful compared with nonpainful heat $\left(t_{(14)}=\right.$ $8.377, p<0.001)$ and cold $\left(t_{(14)}=5.684, p<0.001\right)$. Within both painful and nonpainful conditions, slope values were significantly higher for heat compared with cold stimuli $\left(t_{(14)}=2.789\right.$, $p=0.015)$. Urge to move and intensity slopes values significantly correlated in all conditions: painful heat $(r=0.56, p=0.029)$, painful cold $(r=0.54, p=0.038)$, nonpainful heat $(r=0.53, p=$ $0.041)$, and nonpainful cold $(r=0.83, p<0.001)$.

\section{fMRI}

Main effects of pain, button-press, and temperature

The main effect of pain reveals areas that respond to painful stimulation regardless of action execution. It necessarily ex- 


\section{PAIN RESPONSE}

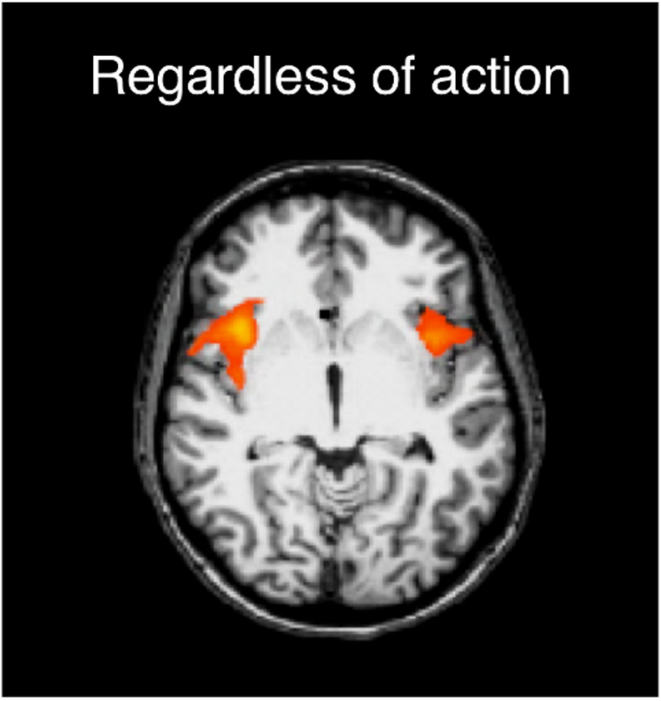

Reaction Times - Beta Values Correlations

PAIN

NO PAIN

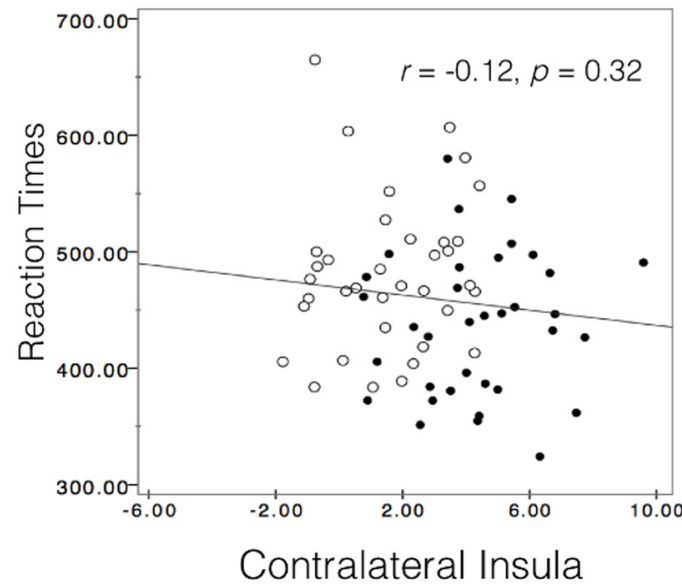

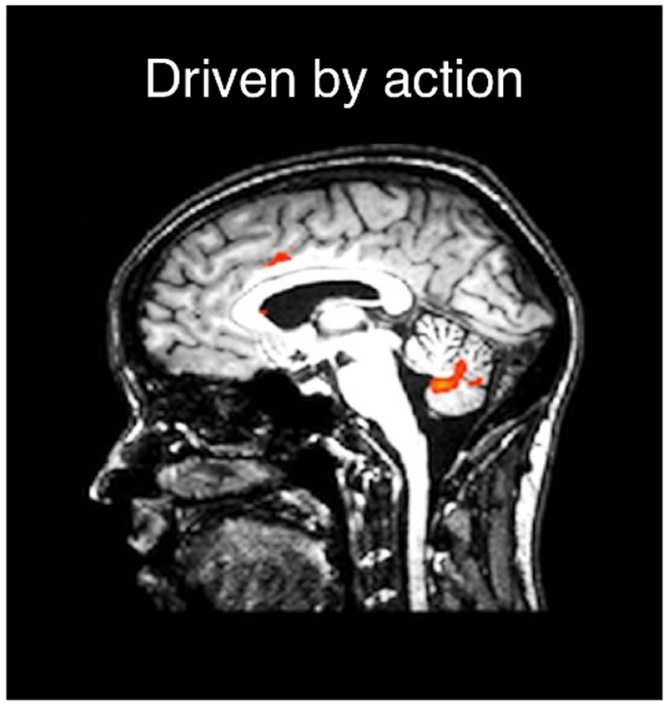

Reaction Times - Beta Values Correlations PAIN NO PAIN

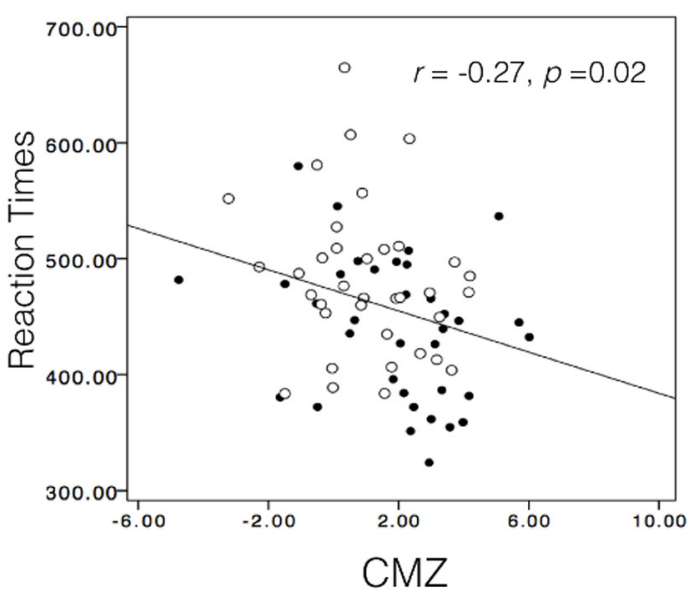

Figure 3. BOLD signal changes regardless of action (left) and driven by action (right) during pain. Top left, Activation map shows bilateral insular activation for the main effect of pain (pain $>$ nonpain, regardless of task). Left bottom, BOLD in anterior insula contralateral to the response hand showed no significant correlation with RTs. Right top, CCZ and cerebellum respond during action regardless of painful stimulation in a conjunction between painful (pain press $>$ pain no-press) and nonpainful (nonpain press $>$ nonpain no-press) action conditions. Right bottom, Trial-by-trial correlation of BOLD and RTs in the CCZ. All activation maps were thresholded at $p<0.005$ at a whole-brain-corrected familywise error of $p<0.05$ on the cluster level for all voxels in the brain volume. Images are presented in radiological convention, with the left hemisphere shown on the right side.

cludes action-related signal variance because the action factor is distributed throughout the experimental design. This contrast for the main effect of pain (all painful vs all nonpainful conditions) activated bilateral anterior insula (Fig. 3, left), frontal operculum, and middle frontal gyrus. For the main effect of nonpainful stimulation, bilateral somatosensory cortex and posterior parietal cortex were activated alongside clusters in bilateral frontal, temporal, and occipital lobes. The main effect of action regardless of painful stimulation (all button-press vs all nonbutton-press conditions) activated cortex contralateral to the response hand in MCC with a cluster at the Vca line (likely in the caudal cingulate motor zone [CCZ]), SMA, precentral and postcentral gyri, parietal operculum and insula, and bilaterally in thalamus, striatum, and cerebellum.
There was no significant activation for the reverse contrast (all nonbutton-press vs all button-press). The main effect of heat stimulation (all heat vs all cold conditions) revealed activation in bilateral somatosensory cortex and cingulate cortex and activation on the right side in parietal operculum, frontal cortex, thalamus, and cerebellum. The reverse contrast (cold vs heat) revealed no significant activations in a whole-brain analysis. A complete list of activation clusters for the main effects of pain, motor, heat, and nonpainful stimulation is presented in Table 1.

Motor-related responses during pain

The central aims of the study were as follows: (1) to identify areas in which action-related processing is engaged during pain; and 
Table 1. Activations for effects of painful stimulation (all pain vs all nonpain conditions), nonpain stimulation (all nonpain vs all pain conditions), motor response (all press vs all no-press conditions), and heat stimulation (all heat vs all cold conditions) $^{a}$

\begin{tabular}{|c|c|c|c|}
\hline Brain region/contrast & $\begin{array}{l}\text { Peak coordinates } \\
\text { (Talairach) }\end{array}$ & $\begin{array}{l}\text { Maximum } \\
t \text {-score }\end{array}$ & $\begin{array}{l}\text { Cluster size } \\
\left(\mathrm{mm}^{3}\right)\end{array}$ \\
\hline \multicolumn{4}{|c|}{ Main effect: pain (all pain > all nonpain) } \\
\hline MFG & $42,46,18$ & 5.51 & 1521 \\
\hline MFG & $-37,37,12$ & 4.41 & 415 \\
\hline Anterior insula & $35,13,6$ & 8.93 & 6524 \\
\hline Anterior insula & $-34,7,12$ & 5.85 & 3679 \\
\hline Posterior insula & $38,20,18$ & 6.62 & 678 \\
\hline Frontal/parietal operculum & $56,7,5$ & 5.64 & 1401 \\
\hline Frontal operculum & $-49,7,9$ & 5.06 & 1162 \\
\hline \multicolumn{4}{|c|}{ Main effect: nonpain (all nonpain > all pain) } \\
\hline SFG & $5,46,-1$ & 6.99 & 113 \\
\hline SFG & $-14,42,6$ & 5.25 & 28 \\
\hline MFG & $-24,8,52$ & 561 & 153 \\
\hline MFG & $26,4,51$ & 5.36 & 50 \\
\hline Precentral gyrus & $-30,-23,49$ & 7.39 & 495 \\
\hline Precentral gyrus & $-54,-2,30$ & 6.231 & 312 \\
\hline Precentral gyrus & $35,-20,47$ & 7.71 & 86 \\
\hline Postcentral gyrus & $43,-18,43$ & 8.19 & 2497 \\
\hline Postcentral gyrus & $-2,-43,52$ & 6.91 & 1033 \\
\hline Postcentral gyrus & $-53,-17,35$ & 10.03 & 315 \\
\hline Postcentral gyrus & $-3,-36,55$ & 6.78 & 19 \\
\hline STS & $-53,-9,-5$ & 5.77 & 999 \\
\hline STS & $53,-6,-12$ & 5.24 & 71 \\
\hline Retroinsula & $-42,-34,18$ & 5.21 & 154 \\
\hline Superior occipital gyrus & $-21,-77,29$ & 6.74 & 1055 \\
\hline Superior occipital gyrus & $44,-69,18$ & 6.13 & 336 \\
\hline Superior occipital gyrus & $24,-73,31$ & 5.6 & 109 \\
\hline Collateral sulcus & $-29,-43,-6$ & 5.99 & 96 \\
\hline \multicolumn{4}{|c|}{$\begin{array}{l}\text { Main effect: motor response (all press }> \\
\text { all no-press) }\end{array}$} \\
\hline SMA & $-2,4,46$ & 4.22 & 349 \\
\hline Midcingulate cortex & $-4,1,45$ & 4.83 & 2480 \\
\hline Precentral gyrus & $-37,-20,54$ & 6.51 & 3152 \\
\hline Postcentral gyrus & $-37,-35,57$ & 5.93 & 6751 \\
\hline Anterior insula & $47,10,3$ & 4.97 & 500 \\
\hline Posterior insula & $-40,-5,9$ & 5.24 & 3659 \\
\hline Parietal operculum & $-46,-23,15$ & 5.47 & 1191 \\
\hline Cerebellum & $-1,-56,-21$ & 9.39 & 10908 \\
\hline Cerebellum & $17,-50,-24$ & 6.69 & 8105 \\
\hline Cerebellum & $-13,-65,-15$ & 5.36 & 2481 \\
\hline Thalamus & $-13,-17,9$ & 6.65 & 2077 \\
\hline Thalamus & $11,-11,6$ & 4.81 & 875 \\
\hline Striatum & $-19,19,0$ & 11.52 & 10612 \\
\hline Striatum & $17,-5,24$ & 6.07 & 3482 \\
\hline \multicolumn{4}{|c|}{ Main effect: heat (all heat $>$ all cold) } \\
\hline SFG & $8,43,18$ & 4.74 & 363 \\
\hline SFG & $2,22,57$ & 4.06 & 198 \\
\hline SFG & $5,40,49$ & 4.11 & 146 \\
\hline MFG & $41,40,3$ & 4.71 & 147 \\
\hline IFG & $54,10,6$ & 5.67 & 423 \\
\hline Cingulate sulcus & $2,-17,45$ & 5.11 & 435 \\
\hline Cingulate sulcus & $-13,-26,48$ & 4.59 & 192 \\
\hline Anterior cingulate cortex & $5,-11,33$ & 4.68 & 822 \\
\hline Subgenual cingulate gyrus & $-4,16,0$ & 5.52 & 147 \\
\hline Parietal operculum & $44,1,15$ & 5.13 & 290 \\
\hline Postcentral sulcus & $32,-41,54$ & 4.72 & 1171 \\
\hline Postcentral sulcus & $-37,-38,51$ & 4.93 & 987 \\
\hline Postcentral suclus & $14,-47,60$ & 5.27 & 285 \\
\hline Intraparietal sulcus & $-37,-53,48$ & 5.27 & 625 \\
\hline Superior parietal lobe & $-7,-65,51$ & 3.91 & 138 \\
\hline Retroinsula & $-28,-26,15$ & 5.46 & 556 \\
\hline
\end{tabular}

Table 1. Continued

\begin{tabular}{lcll}
\hline Brain region/contrast & $\begin{array}{l}\text { Peak coordinates } \\
\text { (Talairach) }\end{array}$ & $\begin{array}{l}\text { Maximum } \\
\text {-score }\end{array}$ & $\begin{array}{l}\text { Cluster size } \\
\left(\mathrm{mm}^{3}\right)\end{array}$ \\
\hline Retroinsula & $29,-23,15$ & 5.73 & 322 \\
Parietal operculum & $44,1,15$ & 5.13 & 287 \\
Cuneus & $-25,-59,6$ & 4.68 & 222 \\
Cuneus & $26,-56,6$ & 5.28 & 219 \\
Calcarine sulcus & $-16,-80,6$ & 5.11 & 147 \\
Thalamus & $17,-17,23$ & 4.67 & 224 \\
Cerebellum & $2,-68,-21$ & 4.14 & 275 \\
\hline
\end{tabular}

${ }^{a}$ All contrasts thresholded at a whole-brain familywise error-corrected level of $p<0.05$.

MFG, Middle frontal gyrus; SFG, superior frontal gyrus; IFG, inferior frontal gyrus; SMA, supplementary motor area; STS, superior temporal sulcus.

(2) to determine whether activation during action can account for such activation during pain. To explore this, two separate planned contrasts were performed: (1) motor responses during painful thermal stimulation ("pain press"; button presses during painful conditions vs painful conditions without button press response); and (2) motor responses during nonpainful thermal stimulation ("nonpain press"; button presses during nonpainful conditions vs nonpainful conditions without button press response). The first contrast identified areas activated when pain and action co-occur, and the second contrast isolated actionrelated activations during nonpainful stimulation for comparison with action-related activations during pain.

The "pain press" contrast for motor responses during painful stimulation revealed clusters bilaterally in MCC (putative CCZ), thalamus, and cerebellum, left motor and sensory cortices (precentral and postcentral gyri), left frontal operculum, and substantia nigra/red nucleus and right anterior insula (Fig. 4A, orange). The "nonpain press" contrast for motor responses during innocuous stimulation revealed clusters in bilateral MCC and cerebellum, left motor and sensory cortices (precentral and postcentral gyri), left thalamus, parietal cortex, frontal operculum, and mid-insula (Fig. $4 A$, blue; Table 2).

Areas involved in voluntary action during pain may be specific to pain or their contribution to pain may be general across painful and nonpainful stimulation. To determine any common activation by button press responses during both painful and nonpainful stimulation, we performed a conjunction of the "pain press" and "nonpain press" contrasts, thresholded at $p=0.005$. This analysis revealed clusters in left MCC, primary motor cortex, thalamus, and cerebellum. A complete list of activation clusters for the effects of motor factors is presented in Table 2.

\section{Correlations with behavior in ROIs}

Areas in which activation shows a relationship with response speed may contribute to reaction time advantages during painful stimulation. To identify such areas, mean RTs per condition for each participant were tested for correlations with BOLD activations within each ROI yielded by the "conjunction" contrast (Table 2). The CCZ cluster was the only conjunction ROI in which a correlation was found. Here, RTs correlated negatively with BOLD, showing greater BOLD responses for faster RTs trial by trial $(r=-0.27, p=0.02)$ (Fig. 3 , right). In contrast, no significant correlations were found among ROIs yielded by the main effect of pain contrast (pain vs nonpain), all $p>0.05$. Figure 3 shows scatterplots of the significant correlation in CCZ compared with the nonsignificant correlation in left anterior insula (contralateral to the response hand), which suggests a functional dissociation in the roles of these areas during pain processing. 


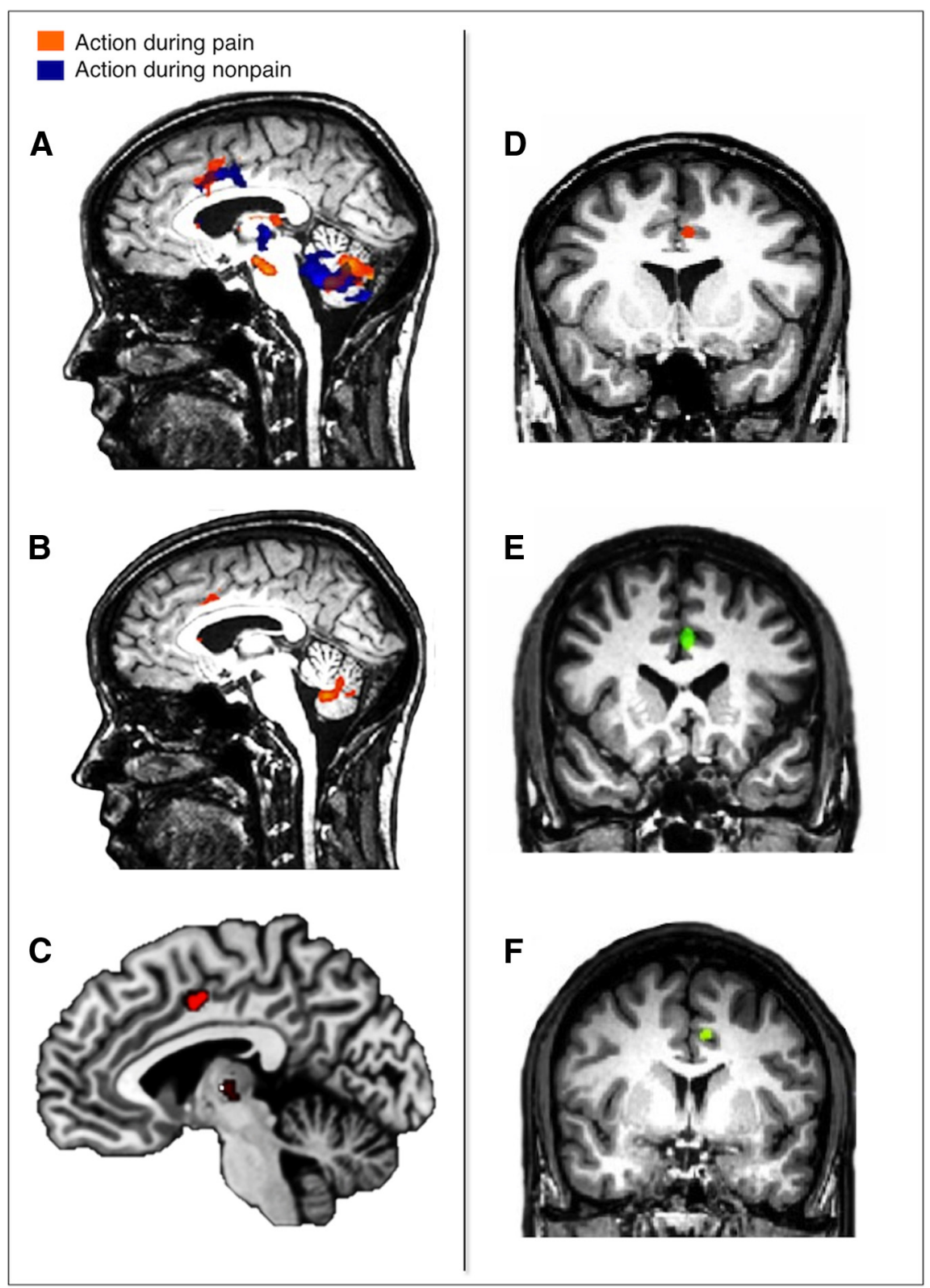

Figure 4. Left, BOLD activation contingent on the motor response factor. $A$, Activation maps for motor responses during painful stimulation (orange) and during nonpainful stimulation (blue), and their overlap (magenta). $\boldsymbol{B}$, Clusters in the $C(Z$, thalamus, and cerebellum for action during both painful and nonpainful stimulation (conjunction contrast). C, ALE meta-analysis for intersection of activations reported for cutaneous pain $(n=814)$, action execution $(n=4019)$, and action preparation $(n=92)$. The resulting midcingulate cluster coincides with the $C \mathrm{CZ}$ activation in the fMRI experiment. All activation maps were thresholded at $p<0.001$ at a whole-brain-corrected familywise error of $p<0.05$ on the cluster level for all voxels in the brain volume. ALE maps were thresholded at a false discovery rate of $q<0.05$; intersection map thresholded at $p<0.05$, corrected. The left hemisphere is shown in all figures. Right, CMZ clusters in single- and double-sulcus variants for pain press contrast. $\boldsymbol{D}$, Peak pain press activation for the whole group $(n=18)$ appears in the sulcus. $E$, Peak activation for single-sulcus variants $(n=12)$ fell on the dorsal bank of the cingulate sulcus $(-2,16,35) . \boldsymbol{F}$, Peak activation for double-sulcus variants $(n=6)$ fell within the depth of the cingulate sulcus $(-5,4,39)$. Activation was thresholded at $20 \%$ below the cluster's peak voxel value for each group ( $t=5.53$ for single, $t=3.72$ for double).

\section{BOLD changes in "pain press" ROIs}

To rule out the possibility that some "pain press" clusters could show interactions among factors, rather than being driven by main effects of action, mean $\beta$ values from clusters activated by the "pain press" contrast (Table 2 ) were submitted to a $2 \times 2 \times 2$ repeated-measures ANOVA with three within-subject factors: noxiousness (painful or nonpainful), temperature (heat or cold), and task (press, no-press). There were no interactions among these in any ROIs. The CCZ, thalamus, left striatum, and cerebellar ROIs were the only clusters that showed a main effect of task without a main effect of pain, indicating unique contributions to action during pain: $F_{(1,17)}=27.07, p=0.000072$ for $\operatorname{CCZ}(2,13,30) ; F_{(1,17)}=52.34, p=$ 0.000001 and $F_{(1,17)}=20.39, p=$ 0.000305 for thalamus clusters $(-10,-2$, 12 ; and $5,-17,12$; respectively); $F_{(1,17)}=$ $60.34, p=0.000001$ for left striatum $(-25,-14,3) ; F_{(1,17)}=23.28, p=$ 0.00016 for left cerebellum $(-4,-68$, $-14)$; and $F_{(1,17)}=51.93, p=0.000001$ for right cerebellum $(14,-62,-27)$.

Of these, thalamus and left striatum also showed a main effect of temperature, $F_{(1,17)}=4.91, p=0.041$ for thalamus $(5$, $-17,12)$, and $F_{(1,17)}=6.35, p=0.022$ for left striatum $(-25,-14,3)$. Within the more restricted set of CCZ voxels defined by the conjunction contrast, there was also a main effect of temperature $\left(F_{(1,17)}=5.71\right.$, $p=0.029)$, with estimated marginal means were higher in press ( mean $=1.45$, SD 2.04) compared with no-press conditions (mean $=-0.36, \mathrm{SD}=2.12)$, and higher for heat $($ mean $=0.24, \mathrm{SD}=2.12)$ compared with cold (mean $=0.16$, SEM $=2.23$ ).

\section{Cingulate sulcal anatomy}

In nonhuman primates, CMA lies within the cingulate sulcus (Picard and Strick, 1996). Determining whether our putative human CCZ activation likewise fell in the sulcus would add to existing data on the homology of human CCZ with primate CMA. To do so, systematic differences in interindividual cingulate anatomy must be accounted for. A major way in which human cingulate anatomy varies among individuals is in the presence of a single or double cingulate sulcus (Vogt, 2005; Shackman et al., 2011). In neuroimaging data, double sulcal anatomy can affect localization through "displacement" of the averaged signal either when an additional gyrus runs parallel to the cingulate gyrus in some individuals, or when additional gyral/sulcal formations occur at any point along the $y$-axis. Here, the MCC activation appears within the sulcus on the averaged group map (Fig. 4D). To investigate whether this localization was affected by individual anatomical differences, we divided the data into two groups based on sulcal anatomy. Of the 18 participants, 12 individuals had a single sulcus and 6 had a double sulcus in the left hemisphere where the painmotor conjunction cluster was located.

Peak activations fell in the depth of the cingulate sulcus for the double-sulcus group (Fig. $4 F$ ). In the single-sulcus group, the cluster spread from the dorsal bank of the sulcus toward the 


\begin{tabular}{|c|c|c|c|}
\hline Brain region/contrast & $\begin{array}{l}\text { Peak coordinates } \\
\text { (Talairach) }\end{array}$ & $\begin{array}{l}\text { Maximum } \\
t \text {-score }\end{array}$ & $\begin{array}{l}\text { Cluster size } \\
\left(\mathrm{mm}^{3}\right)\end{array}$ \\
\hline
\end{tabular}

Movement: pain press (pain press $>$ pain no-press)

Midcingulate cortex

Precentral gyrus

Postcentral gyrus

Supramarginal gyrus

Anterior insula

Cerebellum (vermis VI)

Cerebellum (lobule V/VI)

Cerebellum (lobule VI)

Thalamus

Thalamus

Striatum (caudate)

Striatum (caudate)

Red nucleus/substantia nigra

Movement: no-pain press (no-pain press $>$ no-pain no-press)

Midcingulate cortex

Postcentral gyrus

Postcentral gyrus

Midinsula

Cerebellum (vermis)

Cerebellum (lobule V/VI)

Thalamus

Striatum (caudate-body)

Striatum (caudate-body)

Striatum (putamen)

Conjunction

Midcingulate cortex

Precentral gyrus

Postcentral gyrus

Frontal operculum

Cerebellum (vermis)

Cerebellum (lobule V/VI)

Thalamus

Striatum (caudate-body)

Red nucleus/substantia nigra 760 202 2431 3146 2182 2563

$\begin{array}{crr}2,13,30 & 4.32 & 374 \\ -35,-23,60 & 4.09 & 751 \\ -31,-32,63 & 4.32 & 374 \\ -52,-32,39 & 4.79 & 760 \\ 32,13,12 & 4.48 & 202 \\ -1,-65,-12 & 6.73 & 2431 \\ 14,-62,-27 & 5.54 & 3146 \\ -4,-68,-14 & 5.81 & 2182 \\ -10,-2,12 & 6.96 & 2563 \\ 5,-17,12 & 8.22 & 1508 \\ -25,-14,3 & 7.07 & 5576 \\ 23,4,3 & 5.49 & 1600 \\ -4,17,-9 & 6.22 & 1312\end{array}$

$-1,7,39$
$-49,-29,45$

5.77

5.64

1058

$-37,-29,57 \quad 4.65$

$-43,-2,6 \quad 10.14$

$3,-46,-18 \quad 8.09$

$14,-50,-24 \quad 8.09$

$-1,-20,6 \quad 5.93$

$-16,-11,21 \quad 4.69$

$8,19,15 \quad 5.79$

$-28,-5,0 \quad 3.68$

$-1,10,36 \quad 3.58$

$-37,20,58$

$-37,-35,57$

$-46,7,3$

4.07

4.15

3.96

$-1,-56,-21 \quad 5.66$

$17,-50,-24 \quad 4.88$

$-10,-20,9 \quad 4.26$

$-16,-20,18 \quad 4.11$

$-4,-23,-9 \quad 4.16$

374

751
${ }^{a}$ Thermal stimulation was delivered to the left hand, and responses were made with the right. All contrasts thresholded at a whole-brain familywise error-corrected level of $p<0.05$.

crown of the cingulate gyrus (Fig. 4E). This localization within the fundus and dorsal bank is consistent with the location of primate dorsal CMA (Picard and Strick, 1996).

\section{Meta-analysis}

We used the BrainMap database (Fox and Lancaster, 2002; Laird et al., 2005) and GingerALE software (Turkeltaub et al., 2002; Eickhoff et al., 2009) to determine the functional localization of pain- and action-related activations over a total of 305 studies and 4929 subjects. Three separate meta-analyses were performed to produce activation likelihood maps for (1) pain, (2) action execution, and (3) action preparation. (Because an action component of pain may involve covert motor processing, action preparation was included to capture activation associated with action planning or action intention.)

To discover voxel clusters activated for pain and action execution and action preparation, a three-way intersection (conjunction) analysis of these ALE maps, thresholded at $p<0.05$, was performed. This analysis revealed clusters in bilateral MCC
$(-5,0,38$; and $5,10,38)$, as well as $\operatorname{SMA}(0,5,52)$, left dorsal precentral gyrus $(-38,-19,54)$, bilateral thalamus $(-7,-16,8$; $-8,-13,2$; and $16,-12,8)$, bilateral caudate/putamen $(17,6,2$; and $34,16,1$ ), and bilateral midinsula (middle short gyrus; -38 , 14,1 ; and $34,16,1$ ). The activation cluster from the present fMRI study coincided with the left MCC activation cluster from this conjunction map of pain, action execution, and action preparation $(-5,0,38)$ (Fig. $4 B, C)$.

\section{Discussion}

We hypothesized that pain directly recruits regions with a wider role in motivated voluntary action (e.g., medial prefrontal areas) (Walton et al., 2004). To explore this, voluntary action was controlled for by distributing a button-press task throughout the thermal stimulation conditions of this fMRI experiment. This allowed identification of areas that contribute to an action component of pain, and revealed pivotal regions in which making or suppressing a voluntary action accounted for pain-related neural responses.

\section{Activations accounted for by voluntary action}

Action during pain ("pain press") engaged MCC, thalamus, motor cortex, cerebellum, left frontal operculum, and right frontal operculum/anterior insula, compared with pain without action. Pressing the button during nonpainful stimulation ("nonpain press") engaged a similar group of areas. Main effects contrasts pointed to a disjunction between pain and action variables in several areas, including MCC, motor cortex, and cerebellum: although these areas were activated for the main effect of action (press vs nonpress), they showed no activation for pain per se (pain vs nonpain). This disjunctive effect likely arises because the action-related regressors in the model account for any motor processing variance in the BOLD signal during pain. ANOVAs on "pain press" ROIs confirmed that the MCC cluster was the only region showing a main effect of action without a main effect of pain.

To determine further whether these activations could be accounted for by voluntary action processing, we performed a conjunction analysis between the "pain press" and "nonpain press" maps. This revealed activation in MCC, motor cortices contralateral to the response hand, thalamus, and the cerebellum. Each of these regions has been implicated in the "pain neuromatrix" (e.g., Talbot et al., 1991; Melzack, 1999; Peyron et al., 2000; Iannetti and Moreaux, 2010). Action during innocuous stimulation activated right lobule VI of the cerebellum (ipsilateral to response hand) and vermis, whereas action during pain activated left lobule VI (ipsilateral to stimulation), consistent with previous findings (Helmchen et al., 2003; Moulton et al., 2010). The vermis receives projections from motor areas (Coffman et al., 2011), possibly reflecting its role in the adjustment of movements, or even in pain aversiveness (Moulton et al., 2011).

\section{Cingulate motor zones and "adaptive control"}

Primate medial cortical areas contain premotor fields (Dum and Strick, 1996; Picard and Strick, 1996; Dum et al., 2009). These have been notably implicated in pain withdrawal reflex representation in humans (Piché et al., 2010) and voluntary escape actions in monkeys (Dong et al., 1994; Iwata et al., 2005). Our ALE metaanalysis showed that clusters in bilateral MCC and SMA are activated across pain, action execution, and action preparation conditions, reinforcing the hypothesis that their role in pain processing is probably related to their role in the "adaptive control" 
of voluntary action and action preparation (Vogt and Morecraft, 2009; Vogt and Sikes, 2009; Shackman et al., 2011).

The MCC cluster in the fMRI experiment likely falls within a CMZ (Fig. 4A,B). CMZs are postulated to be the human homologs of the monkey CMAs. CMAs have both output to and input from cervical segments of the spinal cord where motoneurons are located (Picard and Strick, 1996; Koski and Paus, 2000; Dum et al., 2009), suggesting that they play a role in the generation and control of movements. Human CMZ subdivisions (Picard and Strick, 1996) are located along the posterior part of MCC ventral to SMA and pre-SMA (Vogt, 2005). When we took individual sulcal anatomy into account (Vogt et al., 2006; Shackman et al., 2011), the peak voxel fell on the upper bank of the sulcus in both single- and double-sulcus variants (Fig. $4 E, F$ ). This strengthens the proposition that the cluster is probably in CCZ, homologue to dorsal CMA within the banks of the monkey cingulate sulcus (Picard and Strick, 1996).

The CCZ cluster was the only area that correlated with RTs, which were faster for pain. This is consistent with EEG results showing that pain-coupled $\gamma$ oscillations from motor areas predicted RTs (Schulz et al., 2012). Here, the relationship of CCZ response to faster RTs was not specific for pain. This is not surprising considering that cortical participation in pain processing is largely multimodal (Mouraux et al., 2011; Liang et al., 2013), involving networks related to orientation (e.g., Vogt et al., 2006), anticipation (e.g., Porro et al., 2003), and attention (e.g., Sprenger et al., 2012), among other functions, which act in the service of behavior.

Instead, part of what is perceived during acute pain may be a motivated urge related to potential courses of action for escape or avoidance (Morrison et al., 2007a, b, 2013; Salomons et al., 2008; Iannetti and Mouraux, 2010; Shackman et al., 2011). This view is increasingly supported by evidence that avoidance behavior is a distinct action category closely coupled with sensorimotor transformation (Cooke et al., 2003; Graziano and Aflalo, 2007; Schulz et al., 2012) and that the magnitude and probability of painful stimulation can guide human behavior in a relatively direct manner (Kurniawan et al., 2010). For thermal stimuli, something hot poses an immediate tissue-damage risk and prompts quick removal of the body part, whereas the risks of cold occur over a longer time scale without prompting such immediate action. Indeed, ratings of movement urge (indexing a motivational aspect of pain processing) showed the sharpest rises for heat pain in a separate group (Fig. 2). In the fMRI group, BOLD responses in the CCZ were significantly higher for heat than cold pain across conditions, even in "no-press" trials in which signal change was generally lower across conditions. Stimuli perceived as more intense and "urgent" may engage motor-related processing, even under conditions in which any overt motor response to pain is inhibited.

\section{Activation regardless of voluntary action}

After the ACC, the insular cortices are most likely to be activated by painful stimulation, specifically the bilateral anterior insulae (AI) and the left posterior insula (PI) (Duerden and Albanese, 2013). Robust bilateral activation of insular cortex for the main effect of pain here, regardless of whether a movement was executed, suggests that the insula's role in pain processing is not necessarily directly linked to voluntary action. AI activation contralateral to the response hand did not correlate with RTs (Fig. 2), in striking contrast to the MCC's tight relationship with action processing.
The PI is more frequently activated by visceral and somatosensory stimulation (Kurth et al., 2010). Here, a PI cluster was also activated by painful stimulation (pain vs nonpain). Evidence from nonhuman primates suggests that PI is positioned to receive nociceptive information conveyed from the spinothalamic tract via thalamic nuclei containing nociceptive neurons (Dum et al., 2009). It is also the only cortical region to reliably produce pain sensations during microstimulation (Ostrowsky et al., 2002; Mazzola et al., 2012) and spikes before other cortical areas during painful epileptic seizures in one patient (Isnard et al., 2011). This suggests that, unlike the cingulate and other cortical areas, PI is uniquely associated with the experiential aspect of pain.

Cortical somesthetic representation may follow a caudorostral "gradient" in the insula in terms of connectivity and roles in distinct cortical networks (Cauda et al., 2011; Cerliani et al., 2012; Deen et al., 2011), reaching a high degree of integration in AI (Craig, 2003). It is likely that the insula integrates nociceptive information into subjective terms (Craig, 2003; Paulus, 2007), and $\mathrm{AI}$ is involved in classifying and anticipating painful stimuli (Wiech et al., 2010). The bilateral insula clusters seen in the ALE meta-analysis may thus reflect pain-related signaling either not closely coupled with voluntary action or more closely coupled with another type of efferent response, such as autonomic regulation (Critchley et al., 2004; Gianaros et al., 2012).

Primary somatosensory cortices are often implicated in pain (Bushnell et al., 1999), but recent evidence indicates that SI activation for pain is not consistent (63\% in Peyron et al., 2000), is poorly reproducible within subjects (44\%; Taylor and Davis, 2009), and has a significant, but relatively small, likelihood of activation during noxious stimulation (Duerden and Albanese, 2013). Salient sensory stimuli can even bypass processing in SI and SII (Liang et al., 2013). A high frequency of SI deactivations to painful stimulation (90\%; Taylor and Davis, 2009) is consistent with the negative BOLD in somatosensory cortices for the main effect of pain, probably reflecting positive signal changes from the reverse contrast (nonpainful vs painful). The main effect of heat did elicit signal in bilateral SI, consistent with the proposal that thermal coding in somatosensory cortices is more related to heat intensity than pain (Moulton et al., 2012).

In conclusion, pain processing in several key areas, particularly the CCZ, is accounted for by a voluntary action factor, whereas their action-related responses are independent of pain. Nevertheless, we consider the functional relationship of action with pain as not separate but integral to the experience of pain, in which generating and regulating voluntary action impulses are partly constitutive of cortical pain processing. In contrast, the AI's contribution is not tightly linked to the control of voluntary action.

\section{References}

Bushnell MC, Duncan GH, Hofbauer RK, Ha B, Chen JI, Carrier B (1999) Pain perception: is there a role for primary somatosensory cortex? Proc Natl Acad Sci U S A 96:7705-7709. CrossRef Medline

Cauda F, D'Agata F, Sacco K, Duca S, Geminiani G, Vercelli A (2011) Functional connectivity of the insula in the resting brain. Neuroimage 55:8-23. CrossRef Medline

Cerliani L, Thomas RM, Jbabdi S, Siero JC, Nanetti L, Crippa A, Gazzola V, D’Arceuil H, Keysers C (2012) Probabilistic tractography recovers a rostrocaudal trajectory of connectivity variability in the human insular cortex. Hum Brain Mapp 33:2005-2034. CrossRef Medline

Coffman KA, Dum RP, Strick PL (2011) Cerebellar vermis is a target of projections from the motor areas in the cerebral cortex. Proc Natl Acad Sci U S A 108:16068-16073. CrossRef Medline

Cooke DF, Taylor CS, Moore T, Graziano MS (2003) Complex movements 
evoked by microstimulation of the ventral intraparietal area. Proc Natl Acad Sci U S A 100:6163-6168. CrossRef Medline

Craig AD (2003) Interoception: the sense of the physiological condition of the body. Curr Opin Neurobiol 13:500-505. CrossRef Medline

Critchley HD, Wiens S, Rotshtein P, Ohman A, Dolan RJ (2004) Neural systems supporting interoceptive awareness. Nat Neurosci 7:189-195. CrossRef Medline

Deen B, Pitskel NB, Pelphrey KA (2011) Three systems of insular functional connectivity identified with cluster analysis. Cereb Cortex 21:1498-1506. CrossRef Medline

Deiber MP, Honda M, Ibañez V, Sadato N, Hallett M (1999) Mesial motor areas in self-initiated versus externally triggered movements examined with fMRI: effect of movement type and rate. J Neurophysiol 81:3065-3077. Medline

Dong WK, Chudler EH, Sugiyama K, Roberts VJ, Hayashi T (1994) Somatosensory, multisensory, and task-related neurons in cortical area $7 \mathrm{~b}(\mathrm{PF})$ of unanesthetized monkeys. J Neurophysiol 72:542-564. Medline

Duerden EG, Albanese MC (2013) Localization of pain-related brain activation: a meta-analysis of neuroimaging data. Hum Brain Mapp 34:109-149. CrossRef Medline

Dum RP, Strick PL (1992) Medial wall motor areas and skeletomotor control. Curr Opin Neurobiol 2:836-839. CrossRef Medline

Dum RP, Strick PL (1996) Spinal cord terminations of the medial wall motor areas in macaque monkeys. J Neurosci 16:6513-6525. Medline

Dum RP, Levinthal DJ, Strick PL (2009) The spinothalamic system targets motor and sensory areas in the cerebral cortex of monkeys. J Neurosci 29:14223-14235. CrossRef Medline

Eickhoff SB, Laird AR, Grefkes C, Wang LE, Zilles K, Fox PT (2009) Coordinate-based activation likelihood estimation meta-analysis of neuroimaging data: a random-effects approach based on empirical estimates of spatial uncertainty. Hum Brain Mapp 30:2907-2926. CrossRef Medline

Farrell MJ, Laird AR, Egan GF (2005) Brain activity associated with painfully hot stimuli applied to the upper limb: a meta-analysis. Hum Brain Mapp 25:129-139. CrossRef Medline

Fox PT, Lancaster JL (2002) Mapping context and content: the BrainMap model. Nat Rev Neurosci 3:319-321. CrossRef Medline

Fruhstorfer F (1976) Conduction in the afferent thermal pathway of man. In: Sensory functions of the skin in primates, with special reference to man (Zotterman Y, ed), pp 355-366. Oxford: Pergamon.

Gianaros PJ, Onyewuenyi IC, Sheu LK, Christie IC, Critchley HD (2012) Brain systems for baroreflex suppression during stress in humans. Hum Brain Mapp 33:1700-1716. Medline

Graziano MS, Aflalo TN (2007) Mapping behavioral repertoire onto the cortex. Neuron 56:239-251. CrossRef Medline

Helmchen C, Mohr C, Erdmann C, Petersen D, Nitschke MF (2003) Differential cerebellar activation related to perceived pain intensity during noxious thermal stimulation in humans: a functional magnetic resonance imaging study. Neurosci Lett 335:202-206. CrossRef Medline

Iannetti GD, Mouraux A (2010) From the neuromatrix to the pain matrix (and back). Exp Brain Res 205:1-12. CrossRef Medline

Isnard J, Magnin M, Jung J, Mauguière F, Garcia-Larrea L (2011) Does the insula tell our brain that we are in pain? Pain 152:946-951. CrossRef Medline

Iwata K, Kamo H, Ogawa A, Tsuboi Y, Noma N, Mitsuhashi Y, Taira M, Koshikawa N, Kitagawa J (2005) Anterior cingulate cortical neuronal activity during perception of noxious stimuli in monkeys. J Neurophysiol 84:1980-1991. CrossRef Medline

Koski L, Paus T (2000) Functional connectivity of the anterior cingulate cortex within the human frontal lobe: a brain-mapping meta-analysis. Exp Brain Res 133:55-65. CrossRef Medline

Kurniawan IT, Seymour B, Vlaev I, Trommershäuser J, Dolan RJ, Chater N (2010) Pain relativity in motor control. Psychol Sci 21:840-847. CrossRef Medline

Kurth F, Zilles K, Fox PT, Laird AR, Eickhoff SB (2010) A link between the systems: functional differentiation and integration within the human insula revealed by meta-analysis. Brain Struct Funct 214:519-534. CrossRef Medline

Kwan CL, Crawley AP, Mikulis DJ, Davis KD (2000) An fMRI study of the anterior cingulate cortex and surrounding medial wall activations evoked by noxious cutaneous heat and cold stimuli. Pain 85:359-374. CrossRef Medline

Laird AR, Fox PM, Price CJ, Glahn DC, Uecker AM, Lancaster JL, Turkeltaub
PE, Kochunov P, Fox PT (2005) ALE meta-analysis: controlling the false discovery rate and performing statistical contrasts. Hum Brain Mapp 25:155-164. CrossRef Medline

Lancaster JL, Tordesillas-Gutiérrez D, Martinez M, Salinas F, Evans A, Zilles K, Mazziotta JC, Fox PT (2007) Bias between MNI and Talairach coordinates analyzed using the ICBM-152 brain template. Hum Brain Mapp 28:1194-1205. CrossRef Medline

Liang M, Mouraux A, Iannetti GD (2013) Bypassing primary sensory cortices: a direct thalamocortical pathway for transmitting salient sensory information. Cereb Cortex 23:1-11. CrossRef Medline

Matelli M, Luppino G, Rizzolatti G (1991) Architecture of superior and mesial area 6 and the adjacent cingulate cortex in the macaque monkey. J Comp Neurol 311:445-462. CrossRef Medline

Mazzola L, Isnard J, Peyron R, Mauguière F (2012) Stimulation of the human cortex and the experience of pain: Wilder Penfield's observations revisited. Brain 135:631-640. CrossRef Medline

Melzack R (1999) From the gate to the neuromatrix. Pain 6 [Suppl]: S121-S126. Medline

Morrison I, Poliakoff E, Gordon L, Downing P (2007a) Response-specific effects of pain observation on motor behavior. Cognition 104:407-416. CrossRef Medline

Morrison I, Peelen MV, Downing PE (2007b) The sight of others' pain modulates motor processing in human cingulate cortex. Cereb Cortex 17:2214-2222. CrossRef Medline

Morrison I, Tipper SP, Fenton-Adams WL, Bach P (2013) "Feeling” others' painful actions: the sensorimotor integration of pain and action information. Hum Brain Mapp 13:1982-1998. CrossRef Medline

Moulton EA, Schmahmann JD, Becerra L, Borsook D (2010) The cerebellum and pain: passive integrator or active participator? Brain Res Rev 65:14-27. CrossRef Medline

Moulton EA, Elman I, Pendse G, Schmahmann J, Becerra L, Borsook D (2011) Aversion-related circuitry in the cerebellum: responses to noxious heat and unpleasant images. J Neurosci 31:3795-3804. CrossRef Medline

Moulton EA, Pendse G, Becerra LR, Borsook D (2012) BOLD responses in somatosensory cortices better reflect heat sensation than pain. J Neurosci 32:6024-6031. CrossRef Medline

Mouraux A, Diukova A, Lee MC, Wise RG, Iannetti (2011) A multisensory investigation of the functional significance of the "pain matrix." Neuroimage 54:2237-2249. CrossRef

Norrsell U, Ullman M (1978) Note on the conduction velocity of warm afferent fibres from the skin of the human leg. Acta Physiol Scand 103: 337-339. CrossRef Medline

Ostrowsky K, Magnin M, Ryvlin P, Isnard J, Guenot M, Mauguière F (2002) Representation of pain and somatic sensation in the human insula: a study of responses to direct electrical cortical stimulation. Cereb Cortex 12:376-385. CrossRef Medline

Paulus MP (2007) Neural basis of reward and craving: a homeostatic point of view. Dialogues Clin Neurosci 9:379-387. Medline

Peyron R, Laurent B, García-Larrea L (2000) Functional imaging of brain responses to pain: a review and meta-analysis. Neurophysiol Clin 30:263288. CrossRef Medline

Picard N, Strick PL (1996) Motor areas of the medial wall: a review of their location and functional activation. Cereb Cortex 6:342-353. CrossRef Medline

Piché M, Arsenault M, Rainville P (2010) Dissection of perceptual, motor and autonomic components of brain activity evoked by noxious stimulation. Pain 149:453-462. CrossRef Medline

Porro CA, Cettolo V, Francescato MP, Baraldi P (2003) Functional activity mapping of the mesial hemispheric wall during anticipation of pain. Neuroimage 19:1738-1747. CrossRef Medline

Salomons TV, Coan JA, Hunt SM, Backonja MM, Davidson RJ (2008) Voluntary facial displays of pain increase suffering in response to nociceptive stimulation. Pain 9:443-448. CrossRef Medline

Schulz E, Tiemann L, Witkovsky V, Schmidt P, Ploner M (2012) $\gamma$ oscillations are involved in the sensorimotor transformation of pain. J Neurophysiol 108:1025-1031. CrossRef Medline

Shackman AJ, Salomons TV, Slagter HA, Fox AS, Winter JJ, Davidson RJ (2011) The integration of negative affect, pain and cognitive control in the cingulate cortex. Nat Rev Neurosci 12:154-167. CrossRef Medline

Shima K, Tanji J (1998) Role for cingulate motor area cells in voluntary 
movement selection based on reward. Science 282:1335-1338. CrossRef Medline

Sprenger C, Eippert F, Finsterbusch J, Bingel U, Rose M, Büchel C (2012) Attention modulates spinal cord responses to pain. Curr Biol 22:10191022. CrossRef Medline

Talairach J, Tournoux P (1988) Co-planar stereotaxic atlas of the human brain. New York: Thieme.

Talbot JD, Marrett S, Evans AC, Meyer E, Bushnell MC, Duncan GH (1991) Multiple representations of pain in human cerebral cortex. Science 251: 1355-1358. CrossRef Medline

Taylor KS, Davis KD (2009) Stability of tactile- and pain-related fMRI brain activations: an examination of threshold-dependent and threshold-independent methods. Hum Brain Mapp 30:1947-1962. CrossRef Medline

Turkeltaub PE, Eden GF, Jones KM, Zeffiro TA (2002) Meta-analysis of the functional neuroanatomy of single-word reading: method and validation. Neuroimage 16:765-780. CrossRef Medline
Vogt BA (2005) Pain and emotion interactions in subregions of the cingulate gyrus. Nat Rev Neurosci 6:533-544. CrossRef Medline

Vogt BA, Morecraft RJ (2009) Cingulate gyrus. In: Encyclopedia of neuroscience (Binder MD, Hirokawa N, ed), pp 722-726. Berlin: Springer.

Vogt BA, Sikes (2009) Cingulate nociceptive circuitry and roles in pain processing: the cingulate premotor pain model. In: Cingulate neurobiology and disease (Vogt BA, ed), pp 311-338. Oxford, Oxford UP

Vogt BA, Vogt L, Laureys S (2006) Cytology and functionally correlated circuits of human posterior cingulate areas. Neuroimage 29:452-466. CrossRef Medline

Walton ME, Devlin JT, Rushworth MF (2004) Interactions between decision making and performance monitoring within prefrontal cortex. Nat Neurosci 7:1259-1265. CrossRef Medline

Wiech K, Lin CS, Brodersen KH, Bingel U, Ploner M, Tracey I (2010) Anterior insula integrates information about salience into perceptual decisions about pain. J Neurosci 30:16324-16331. CrossRef Medline 